\title{
STUDIES OF STRUCTURAL CHANGES IN PAN FIBERS WITH VARIOUS INITIAL STRUCTURES UNDER THE INFLUENCE OF THERMAL TREATMENT IN MEDIA
}

\author{
Ewa Marczak, Piotr Marczak, Sławomir Sztajnowski, Barbara Lipp-Symonowicz \\ Department of Material and Commodity Sciences and Textile Metrology, Lodz University of Technology, Zeromskiego 116, 90-924 Lodz, Poland \\ Correspondence to: Ewa Marczak (e-mail: ewam545@wp.pl)
}

\begin{abstract}
:
The aim of the paper is to assess the range and the mechanisms of transformations of the molecular structure and the physical microstructure of polyacrylonitrile (PAN) fibers produced by various manufacturers under the influence of thermal treatment in different conditions. The thermal treatments were carried out in different media (such as air, water, and steam), at various temperatures, and using different periods of treatment. Changes in the molecular structure were assessed using infrared (IR) absorption spectroscopy and evaluation of the differences in molecular cohesion energy of the fiber material during the dissolution processes. Changes in the fibers' physical microstructure were investigated using densitometric, IR spectrophotometric, and X-ray diffraction methods; for assessment of both the reconstruction process of the paracrystalline matter of the fibers and the changes in the fibers' total orientation, interferential polarization microscopy was used.
\end{abstract}

\section{Keywords:}

Polyacrylonitrile (PAN) fibers, thermal treatment, molecular structure, physical microstructure, Fourier transform infrared (FTIR), wide-angle X-ray scattering (WAXS), critical dissolution time (CDT)

\section{Introduction}

Polyacrylonitrile (PAN) fibers differ in chemical structure from other synthetic fibers. They are produced from two- or threecomponent copolymers [1-3], which contain - in addition to acrylonitrile - small quantities of monomeric units of other comonomers, e.g., itaconic acid, vinyl acetate, methyl acrylate, and sodium allylsulfonate, which improve their mechanical properties and dyeability $[4,5]$.

PAN fibers are also characterized by a clear structural porosity that results from the presence of macromolecular bundles, such as fibrils and aggregates of globular macromolecules, as well as pores (empty spaces), in their morphological structure. The sizes of the fibrils and the pores in a fiber depend on the conditions of its formation and the chemical constitution of the fiber matter [6-10]. Moreover, the fibers are characterized by a low internal orientation and a lack of typical crystalline structure.

The molecular structure of PAN and the diversity of the PAN fiber in terms of its chemical structure are reflected during the specific thermal reconstruction of the material of these fibers through many chemical processes (destruction, cross-linking, and cyclization). The thermal transformation of PAN fibers has become the object of numerous studies [11-20]; however, it has not yet been fully explained due to the fact that the treatment of these fibers under industrial conditions is carried out in various heating media, which affects the mechanism and chemical reconstruction of the polymer, as well as the physical microstructure of the fiber.
The available literature concerning the thermal reconstruction of PAN fibers is mainly devoted to changes occurring in the fiber during the high-temperature treatment connected with making carbon and high-performance fibers [21-27]. Insufficiently explained are the problems of structural changes in the material of the PAN fiber upon thermal treatment and the used production conditions for fibers with different initial chemical constitutions, which in turn are directly connected with the modification of the properties of the fibers designed for textiles.

Thermal treatment of textile-oriented fibers carried out during the manufacturing process, the processing of these fibers into the final product, improvement, and finishing, as well as their use, result - as a rule - in changes in their molecular and supramolecular structures and, thereby, in changes in their properties; the range and mechanism of these changes depend on the temperature, heating time, and medium, as well as the fiber's dynamic state [28-30].

The aim of the present study was to assess the range and mechanism of transformation of the molecular structure of PAN fibers having different initial chemical structures (produced by various manufacturers), as well as assessing their physical microstructure, under the influence of various thermal treatment conditions applied in industrial practice.

The result will establish the basis for deciphering the effects related to changes in, as well as enable the optimization of, the fiber properties, especially the mechanical properties and the dyestuff sorption ability. 


\section{Experimental}

\subsection{Materials}

Commercial PAN fibers with different copolymer compositions, produced by various methods under the trade names Crumeron (Hungary), Nitron (Bielorussia), and Aksa (Turkey), were used for the study. The characteristics of the particular types of PAN fibers, including chemical composition and manufacturing technology, are listed in Table 1 [31, 32].

\subsubsection{Conditions of the thermal treatment of fiber}

The most popular conditions of thermal treatment used in the manufacturing processes of the fibers were applied in the current investigations by varying the temperature, heating time, and medium (water, steam, and air). The thermal treatment program is presented in Table 2. Prior to the thermal treatment in air and steam, fibers were arranged in a layer with even thickness and placed in heating devices. Thermal treatment in water was carried out in cups of an Ahiba Polymat dyeing apparatus. The thermal treatment in air, water, or steam was carried out using fiber in the unstrained state and with the following apparatuses:

- Chamber for thermal tests KBC-125G from WAMED - for treatment with hot air;

- Pressure dyeing apparatus Ahiba Polymat - for hydrothermal treatment;

- Steam sterilizer STS - for treatment with steam.

\subsection{Descriptions of the instrumental methods used}

Various measurement methods were used to assess changes in the selected parameters of molecular and supramolecular structures. Thus, changes in the molecular structure were assessed by the following methods:

- Infrared (IR) absorption spectroscopy and

- measurement of critical dissolution time (CDT) of fiber in a selected solvent to assess changes in the molecular cohesion energy of the fiber material.

Furthermore, changes in the fiber's physical microstructure were analyzed using the following methods:
- Densitometric and IR absorption spectrometric methods for the assessment of changes in the paracrystalline material;

- Interferential polarization microscopy for the determination of the fiber's optical birefringence as a basis for the assessment of changes in the fiber's general orientation; and

- Wide-angle $\mathrm{X}$-ray diffraction method for the selected variants, to confirm the changes in the content of ordered material in fibers.

\subsubsection{Fourier transform IR (FTIR) spectroscopic measurements of the fiber's molecular and supramolecular structures}

FTIR spectroscopic measurements were carried out using isotropic fibrous specimens in the form of tablets [33, 34]. FTIR absorption spectroscopy was used to obtain the spectra of the tablet specimens $[35,36]$, recorded using the expression $A=f(1 / \mathrm{l})(\mathrm{FTIR} 8101 \mathrm{M}$ spectrophotometer; Shimadzu, Tokyo, Japan). The graphic processing of the spectrograms obtained was carried out using the software ACD/Labs Spec Manager, version 4.60

The spectra obtained constituted the basis for the determination of the absorbance $A$ of the selected bands, whose values were used to interpret the changes in the fiber's molecular structure.

Based on the IR absorption spectra of the fibers, the values of the paracrystallinity factor were also determined [37], relating the band of molecular order with a wave number of $\sim 775 \mathrm{~cm}^{-1}$ [38] to the internal standard band. After qualitative and quantitative analyses of the absorption bands obtained, the

Table 2. The thermal treatment program for fibers

\begin{tabular}{|c|c|c|}
\hline \multicolumn{2}{|c|}{ Thermal treatment medium and the parameters used } \\
\hline Air & Water & Steam + air \\
\hline & & $134^{\circ} \mathrm{C}, 0.25 \mathrm{MPa}$ \\
$180^{\circ} \mathrm{C}, 2 \mathrm{~min}$ & $120^{\circ} \mathrm{C}, 10 \mathrm{~min}$ & $5 \mathrm{~min}$ \\
$180^{\circ} \mathrm{C}, 5 \mathrm{~min}$ & $120^{\circ} \mathrm{C}, 15 \mathrm{~min}$ & $134^{\circ} \mathrm{C}, 0.25 \mathrm{MPa}$ \\
& & $15 \mathrm{~min}$ \\
\hline
\end{tabular}

Table 1. Characteristics of the PAN fibers investigated

\begin{tabular}{|c|c|c|c|}
\hline Trade name of fiber & $\begin{array}{c}\text { Crumeron } \\
\text { (Hungary) }\end{array}$ & $\begin{array}{c}\text { Nitron } \\
\text { (Bielorussia) }\end{array}$ & $\begin{array}{c}\text { Aksa } \\
\text { (Turkey) }\end{array}$ \\
\hline Producer & Zoltek & Polymir & Aksa \\
\hline $\begin{array}{c}\text { Chemical composition of the fiber } \\
\text { material }\end{array}$ & $\begin{array}{c}\text { Acrylonitrile 91\%, } \\
\text { Methyl acrylate 8\% } \\
\text { Sodium allylsulfonate 1\% }\end{array}$ & $\begin{array}{c}\text { Acrylonitrile 92\%, } \\
\text { Methyl acrylate 6.3\%, } \\
\text { Itaconic acid 1.7\% }\end{array}$ & $\begin{array}{c}\text { Acrylonitrile } \sim 93 \% \\
\text { Vinyl acetate } \sim 7 \%\end{array}$ \\
\hline Polymerization method & Solution method & Solution method & Suspension method \\
\hline Solvent & Dimethylformamide (DMF) & $\begin{array}{c}\text { Sodium thiocyanate } \\
\text { (NaCNS) }\end{array}$ & Dimethylacetamide (DMA) \\
\hline Spinning method & Wet process & Wet process & Wet process \\
\hline
\end{tabular}


band at $\sim 1,073 \mathrm{~cm}^{-1}$ was used as the internal standard band. The paracrystallinity factor was calculated using the following equation:

$$
x_{I R}=\frac{A_{775}}{A_{1073}}
$$

where $A_{775}$ and $A_{1,073}$ represent the absorbances of the bands at $\sim 775 \mathrm{~cm}^{-1}$ and $\sim 1,073 \mathrm{~cm}^{-1}$, respectively.

\subsubsection{Examination of the fiber's molecular cohesion based on assessment of CDT of fiber}

Changes in the fiber's molecular cohesion were assessed by microscopic observation of the fiber's dissolution in $N, N$ dimethylformamide (DMF). Measurements were carried out at a constant temperature $\left(50^{\circ} \mathrm{C}\right)$ using a microscope with a heated table (Böethius). The preparation containing a single elementary fiber was placed on the microscope table heated up to a temperature of $50^{\circ} \mathrm{C}$ for $3 \mathrm{~min}$. Then, a drop of the solvent with a temperature of $50^{\circ} \mathrm{C}$ was added (initial point of measuring the dissolution time). The disappearance of the fiber image was accepted as the end of the fiber dissolution [39]. For each measurement variant, 10 measurements were made to calculate the average fiber dissolution time.

The measurement of the content of ordered (paracrystalline) PAN fiber material was made on the basis of the paracrystallinity theory of Lindenmeyer and Hosemann [40].

The relationship between the real density and the crystallinity degree of the fiber mass [39] was determined on the basis of the following equation:

$$
x_{m}=\frac{d_{k r}\left(d-d_{a}\right)}{d\left(d_{k r}-d_{a}\right)}
$$

where:

$d$ - fiber's real density $\left[\mathrm{g} / \mathrm{cm}^{3}\right]$,

$d_{\mathrm{kr}}$ - density of ordered (paracrystalline) material $\left[\mathrm{g} / \mathrm{cm}^{3}\right]$, and $d_{\mathrm{a}}$ - density of amorphous material $\left[\mathrm{g} / \mathrm{cm}^{3}\right]$.

For the determination of the fiber's paracrystallinity degree according to the above equation, the following values were used: $d_{\mathrm{kr}}=1.262 \mathrm{~g} / \mathrm{cm}^{3}$ and $d_{\mathrm{a}}=1.110 \mathrm{~g} / \mathrm{cm}^{3}[41]$.

The measurement of the fiber's real density, indispensable for the determination of the paracrystallinity degree, was made by the flotation method using a gradient column maintained at a temperature of $25^{\circ} \mathrm{C}$, with five determinations of the $d$ value for each variant.

\subsubsection{Measurement of the fiber's overall orientation by the optical method (split image technique)}

The fiber optical birefringence parameters were determined by measuring the directional light refraction coefficients in the fiber $\left(n_{\|}, n_{\wedge}\right)$ and then calculating the difference in their values. The technique of homogeneous interferential field with a completely split image was used with an MPI-5 interferential polarization microscope (PZO) [42, 43].

During measurement, the tested fiber was placed in different immersion fluids that showed refraction indexes according to the following dependences:

$$
\begin{aligned}
& \mathrm{n}_{\mathrm{c} 1}<\mathrm{n}_{1} \text { and } \mathrm{n}_{\mathrm{c} 2}>\mathrm{n}_{\perp} \\
& \mathrm{n}_{\mathrm{c} 1}<\mathrm{n}_{\perp} \text { and } \mathrm{n}_{\mathrm{c} 2}>\mathrm{n}_{\text {। }}
\end{aligned}
$$

to meet the following condition:

$$
\left|\frac{n_{c}-n_{\|, \perp}}{d}\right|<<\lambda
$$

where:

$d$ - fiber thickness, and I-wavelength of light.

Liquids with refraction indexes $n_{c 1}=1.5049$ and $n_{c 2}=1.5308$ were used for the measurements. The magnification of the microscope lens was $10 x$. The wavelength of light used was $\mathrm{I}=546 \mathrm{~nm}$. The fiber's directional refraction coefficients were calculated from the following expression:

$$
\mathrm{n}_{\mid, \perp}=\frac{\mathrm{n}_{\mathrm{c} 1} \cdot\left|\Delta \mathrm{p}_{2}\right|+\mathrm{n}_{\mathrm{c} 2} \cdot\left|\Delta \mathrm{p}_{1}\right|}{\left|\Delta \mathrm{p}_{1}\right|+\left|\Delta \mathrm{p}_{2}\right|}
$$

where:

$\mathrm{n}_{\mathrm{c} 1}$ - refraction coefficient of Liquid 1,

$\mathrm{n}_{\mathrm{c} 2}$ - refraction coefficient of Liquid 2 ,

$\left|\Delta p_{1}\right|=\left(\left|p_{1}-p_{2}\right| / 2\right)_{1}-$ prism travel quantity determined for Liquid 1,

$\left|\Delta p_{2}\right|=\left(\left|p_{1}-p_{2}\right| / 2\right)_{2}-$ prism travel quantity determined for Liquid.2.

The average values of optical birefringence were used to calculate the optical birefringence corrected in terms of density according to the following formula:

$$
\Delta n_{\text {cor }}=\frac{\Delta n}{d}
$$

which was used as an index that characterizes the overall fiber orientation [44], with $\Delta \mathrm{n}$ being the fiber optical birefringence and $d$, the fiber density determined by the densitometric method.

\subsubsection{Measurement of the content of ordered (paracrystalline) fiber material using $X$-ray diffractometry}

The measurements were made with an X'Pert PRO diffractometer (PANalytical) with the use of CuKa rays ( $I=$ $0.154 \mathrm{~nm}$ ) and the following parameters of tube operation: accelerating voltage $40 \mathrm{kV}$; intensity of anode current $30 \mathrm{~mA}$. A semiconductor $X^{\prime}$ Celerator was used as the detector. 
The diffraction patterns of powder samples with the same weight $(300 \mathrm{mg})$ were recorded within the range of $2 \theta=5^{\circ}-60^{\circ}$, with a step of $0.016^{\circ}$.

The analysis of diffraction patterns was performed using Hindeleh-Johnson's method [45-47]. In accordance with this method, the theoretical curve is a sum of the peaks corresponding to 1) the diffraction in the crystalline areas and 2) dissipation in the amorphous areas and the curve describing the background.

The determination of the fiber's crystalline phase (crystallinity degree) by wide-angle X-ray scattering (WAXS) measurement requires one to separate the diffraction pattern obtained into components corresponding to the scattering of X-rays in the amorphous and crystalline areas of the polymer. The next step is calculation of the areas under the curves obtained, $A_{\mathrm{a}}$ and $A_{\mathrm{c}}$, respectively. The crystallinity degree $X_{C}$ was determined using the following formula:

$$
X_{\text {C. }}=\frac{A_{C}}{A_{C}+A_{a}}
$$

\section{Results and discussion}

\subsection{Results}

\subsubsection{Measurement results of the fiber's molecular structure by IR absorption spectroscopy}

Changes in the absorption spectra of the untreated fibers are illustrated in Figure 1 and examples of changes after thermal treatment of fibers are shown in Figures 2, 3, and 4; the changes related to a decrease or an increase in the absorbance of the characteristic absorption bands, or the appearance of new bands, were used as indication of the molecular reconstruction of the fibers investigated.

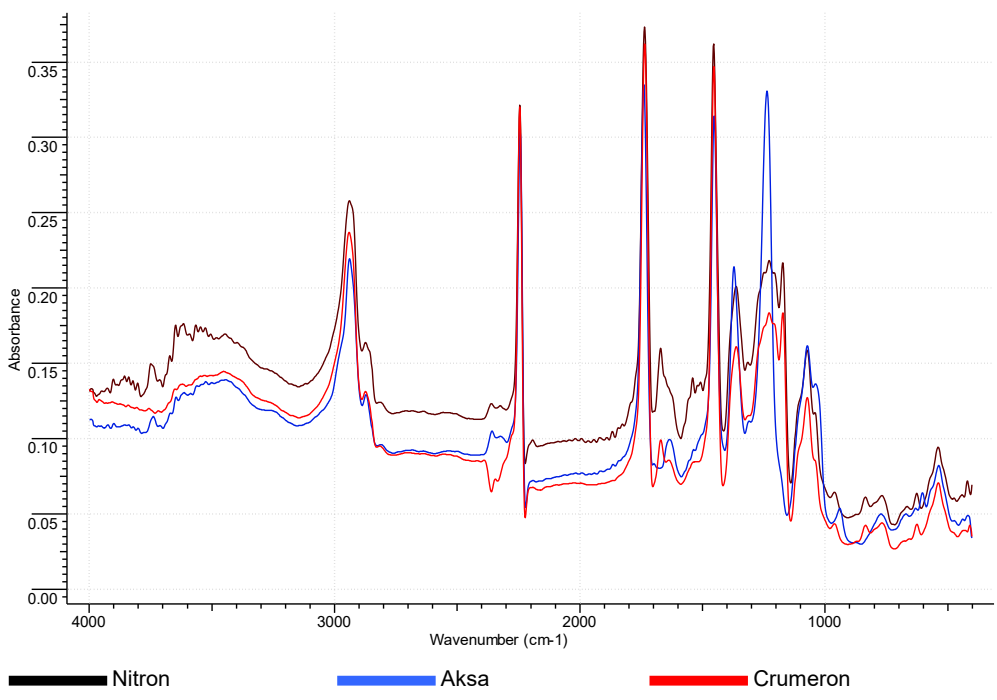

Figure 1. FTIR spectrograms of initial fibers

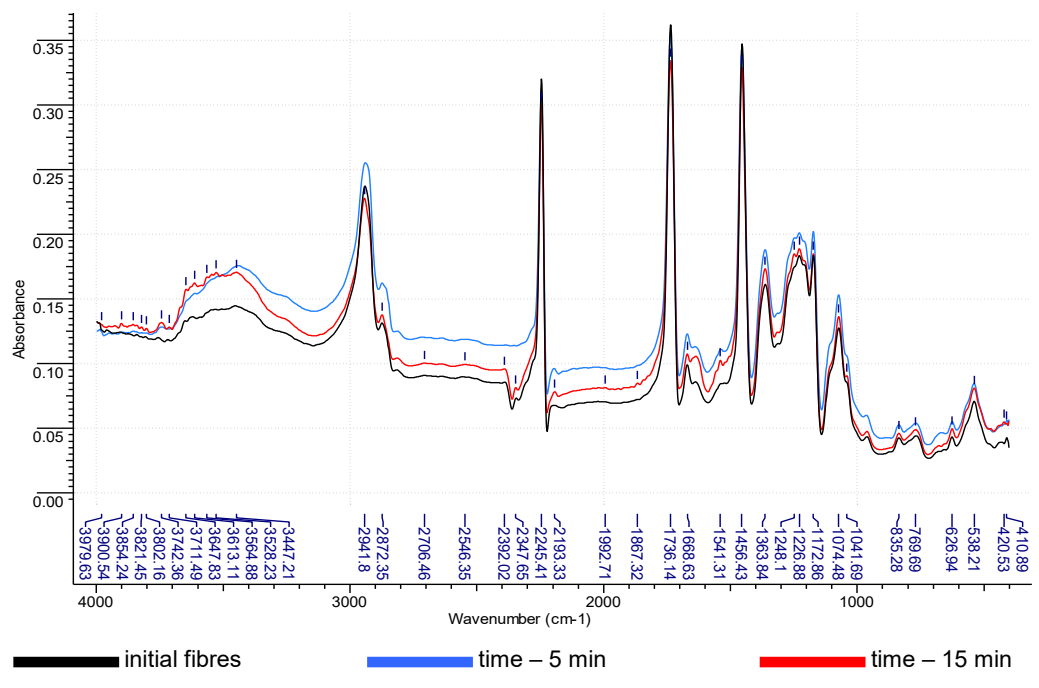

Figure 2. FTIR spectrograms of Crumeron fibers before and after treatment in steam at a temperature of $134^{\circ} \mathrm{C}$. 


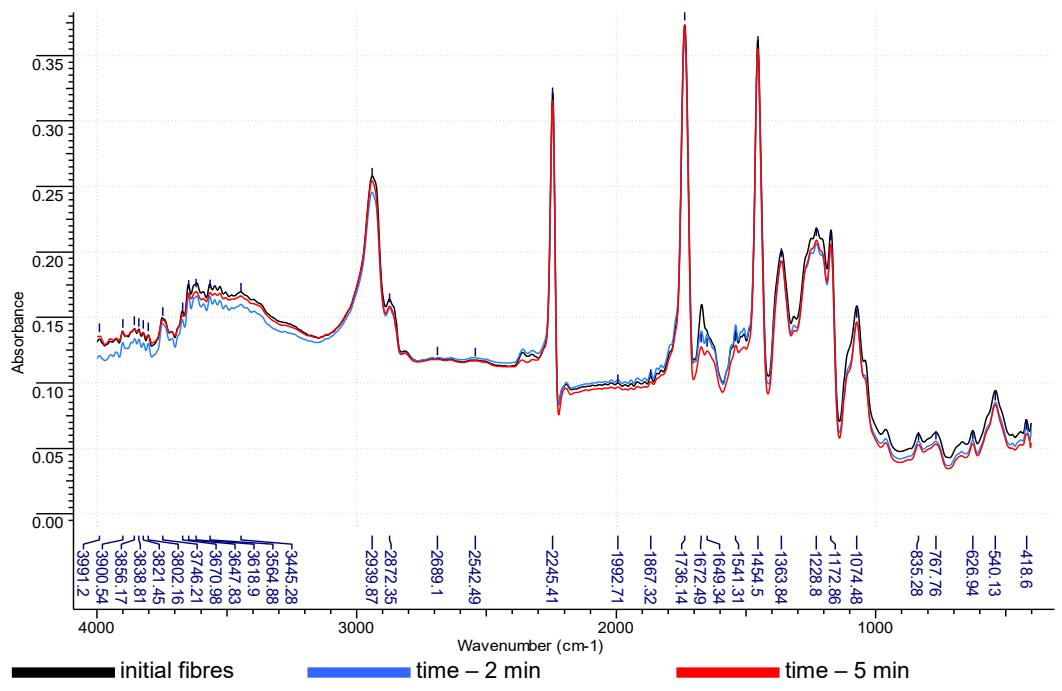

Figure 3. FTIR spectrograms of Nitron fibers before and after treatment in air at a temperature of $180^{\circ} \mathrm{C}$.

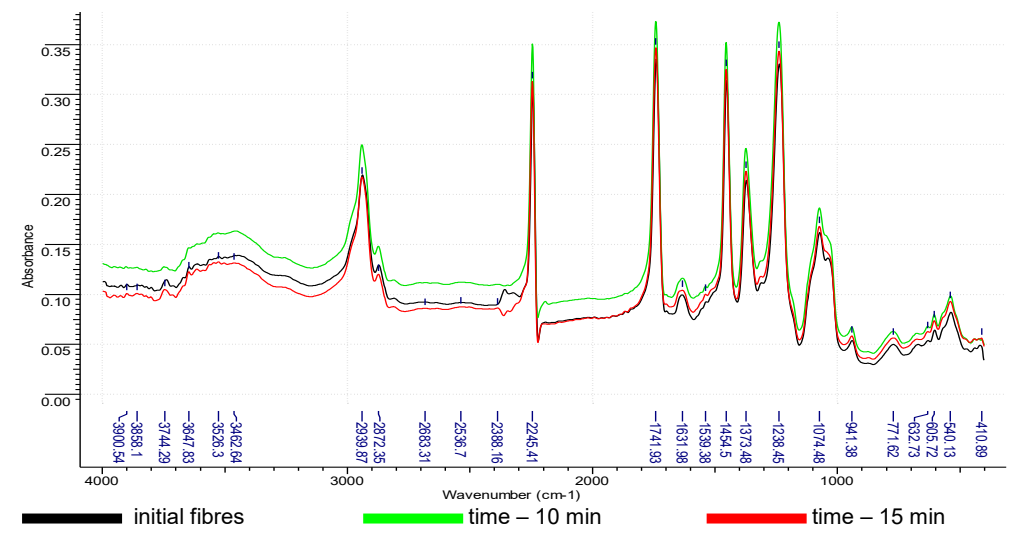

Figure 4. FTIR spectrograms of Aksa fibers before and after treatment in water at a temperature of $120^{\circ} \mathrm{C}$.

The analysis of the spectrograms obtained by FTIR in the form of absorbance values of the characteristic absorption bands $\left(775 \mathrm{~cm}^{-1}, \sim 1,073 \mathrm{~cm}^{-1}\right.$, and $\left.\sim 1,649 \mathrm{~cm}^{-1}\right)$ for the fibers investigated (Nitron fibers, Crumeron fibers, and Aksa fibers) is presented in Table $3 \mathrm{~A}, \mathrm{~B}$, and $\mathrm{C}$, respectively.

\subsubsection{Measurement results of the molecular structure of fiber by the CDT method}

Changes in the molecular coherence of the fiber material are illustrated in Figure $5 \mathrm{~A}, \mathrm{~B}$, and $\mathrm{C}$ on the basis of changes in the values of CDT of the thermally treated fibers as a function of time.

3.1.3 Measurement results of the content of the paracrystalline material in the fiber by the densitometric method

Measurement results of changes in the content of paracrystalline material in the fibers investigated under the influence of thermal treatment for various periods of time are shown in Figure $6 \mathrm{~A}$, $\mathrm{B}$, and $\mathrm{C}$.

\subsubsection{Content of ordered material of fiber measured by IR absorption spectroscopy}

Measurement results of changes in the content of paracrystalline material in the fibers investigated under the influence of thermal treatment for various periods of time are illustrated in Figure 7 $\mathrm{A}, \mathrm{B}$, and $\mathrm{C}$.

\subsubsection{Changes in the overall orientation of fibers measured by the optical method}

Measurement results of changes in the overall orientation of the fibers investigated (in the form of changes in corrected optical birefringence) under the influence of thermal treatment for various periods of time are illustrated in Figure $8 \mathrm{~A}$ and $\mathrm{B}$.

\subsubsection{Content of the ordered material of fiber assessed by the X-ray method}

Measurement results of changes in the content of paracrystalline material for the selected variants of thermal treatment for Nitron and Crumeron fibers in relation to untreated fibers are presented in Table 6. 
Table 3. The absorbance values of chosen absorption bands of the fibers before and after thermal treatment

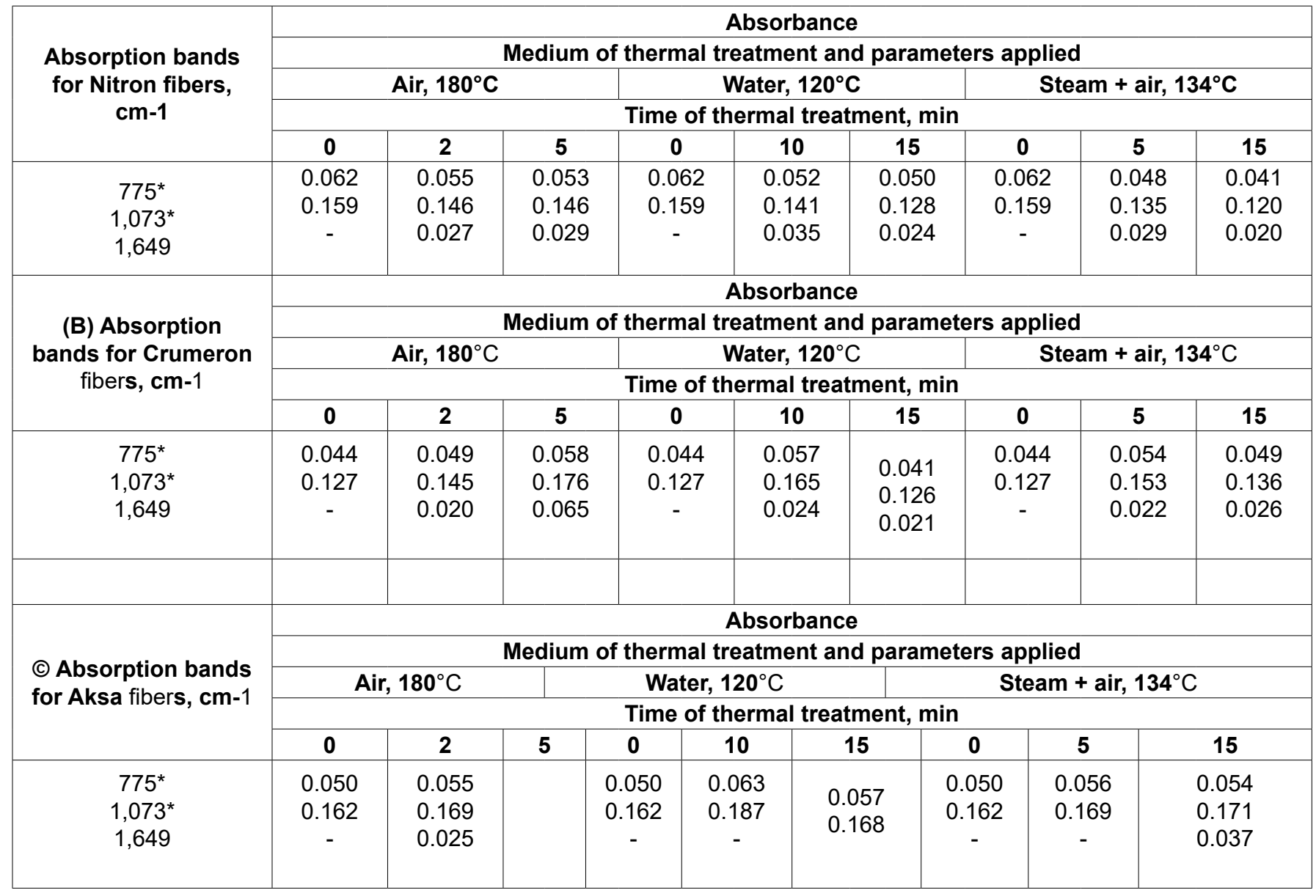

Note: *Bands used for calculating the paracrystallinity factor $X_{\mathbb{R}}$.

Table 4. The densities of fibers before and after thermal treatment

\begin{tabular}{|c|c|c|c|c|c|c|c|c|c|}
\hline \multirow{5}{*}{$\begin{array}{l}\text { Fiber } \\
\text { trade } \\
\text { name }\end{array}$} & \multicolumn{9}{|c|}{ Density, $\mathrm{g} / \mathrm{cm} 3$} \\
\hline & \multicolumn{9}{|c|}{ Medium of thermal treatment and parameters applied } \\
\hline & \multicolumn{3}{|c|}{ Air, $180^{\circ} \mathrm{C}$} & \multicolumn{3}{|c|}{ Water, $120^{\circ} \mathrm{C}$} & \multicolumn{3}{|c|}{ Steam + air, $134^{\circ} \mathrm{C}$} \\
\hline & \multicolumn{9}{|c|}{ Time of thermal treatment, $\min$} \\
\hline & 0 & 2 & 5 & 0 & 10 & 15 & 0 & 5 & 15 \\
\hline Crumeron & 1.1791 & 1.1801 & 1.1820 & 1.17191 & 1.1785 & 1.1782 & 1.1791 & 1.1806 & 1.1804 \\
\hline Nitron & 1.1853 & 1.1860 & 1.1873 & 1.1853 & 1.1841 & 1.1816 & 1.1853 & 1.1850 & 1.1853 \\
\hline Aksa & 1.1790 & 1.1845 & 1.1855 & 1.1790 & 1.1789 & 1.1782 & 1.1790 & 1.1802 & 1.1809 \\
\hline
\end{tabular}

Table 5. The optical birefringence values of fibers before and after thermal treatment

\begin{tabular}{|c|c|c|c|c|c|c|}
\hline \multirow{5}{*}{ Fiber trade name } & \multicolumn{6}{|c|}{ Optical birefringence } \\
\hline & \multicolumn{6}{|c|}{ Medium of thermal treatment and parameters applied } \\
\hline & \multicolumn{3}{|c|}{ Air $180^{\circ} \mathrm{C}$} & \multicolumn{3}{|c|}{ Water $120^{\circ} \mathrm{C}$} \\
\hline & \multicolumn{6}{|c|}{ Time of thermal treatment, min } \\
\hline & 0 & 2 & 5 & 0 & 10 & 15 \\
\hline Crumeron & -0.0016 & -0.0019 & -0.0023 & -0.0016 & -0.0030 & -0.0041 \\
\hline Nitron & -0.0021 & -0.0031 & -0.0038 & -0.0021 & -0.0022 & -0.0025 \\
\hline Aksa & -0.0022 & -0.0036 & -0.0069 & -0.0022 & -0.0039 & -0.0044 \\
\hline
\end{tabular}




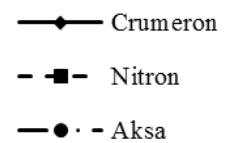

\section{B}

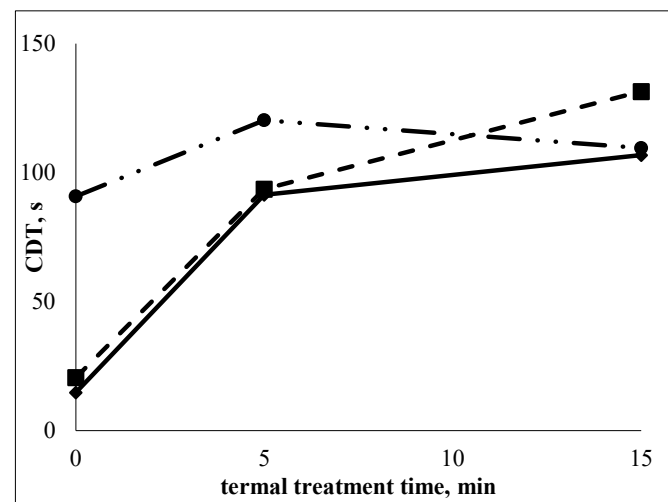

A

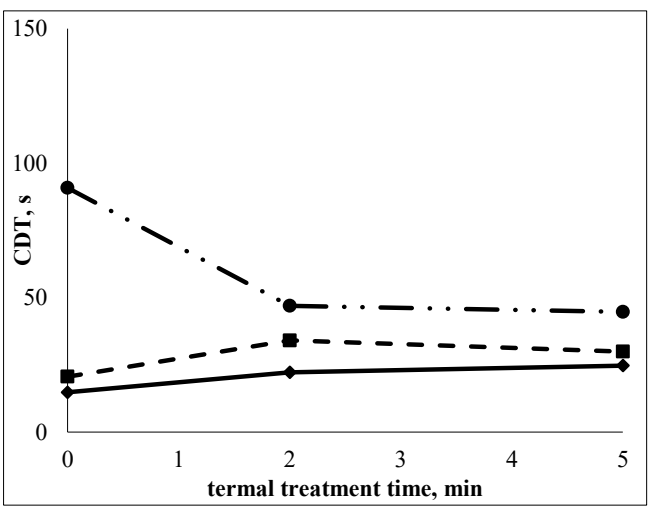

C

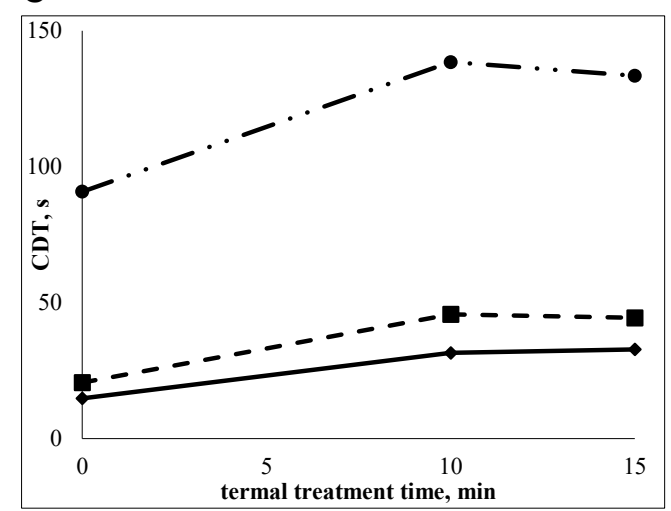

Figure 5. The changes of critical dissolution time (CDT) for the investigated fibers under the influence of thermal treatment: $A)$ in air at temperature $180^{\circ} \mathrm{C}$; B) in steam at temperature $134^{\circ} \mathrm{C}$; and C) in water at temperature $120^{\circ} \mathrm{C}$.
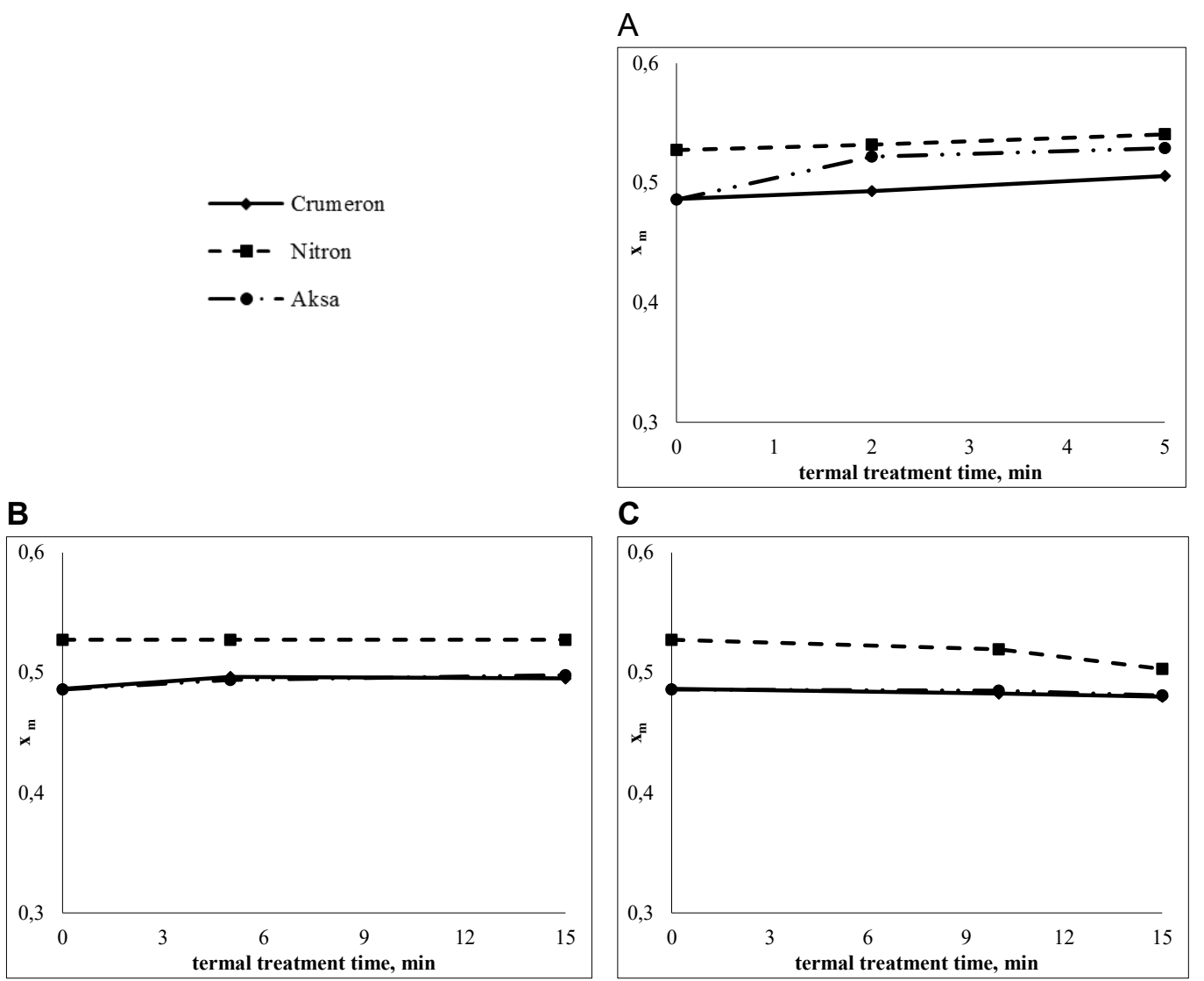

Figure 6. The changes in the content of ordered material (paracrystalline matter) $\mathbf{x m}$ under the influence of thermal treatment for the fibers investigated: $\mathrm{A}$ ) in air at temperature $180^{\circ} \mathrm{C}, \mathrm{B}$ ) in steam at temperature $134^{\circ} \mathrm{C}$, and $\mathrm{C}$ ) in water at temperature $120^{\circ} \mathrm{C}$ as a function of treatment time. 


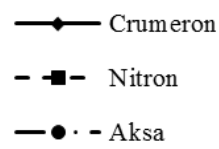

$\mathrm{B}$

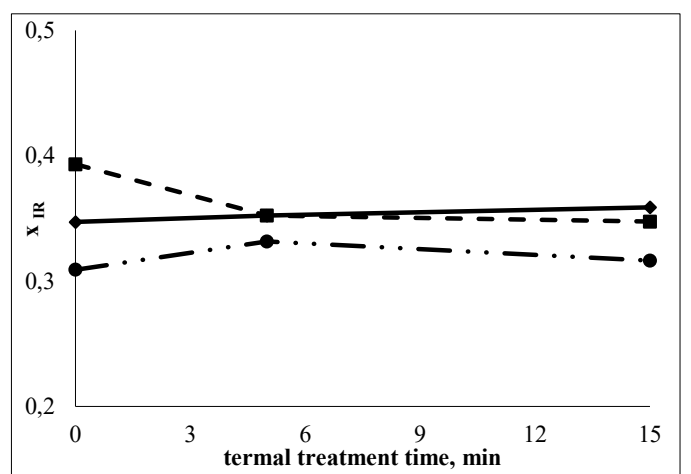

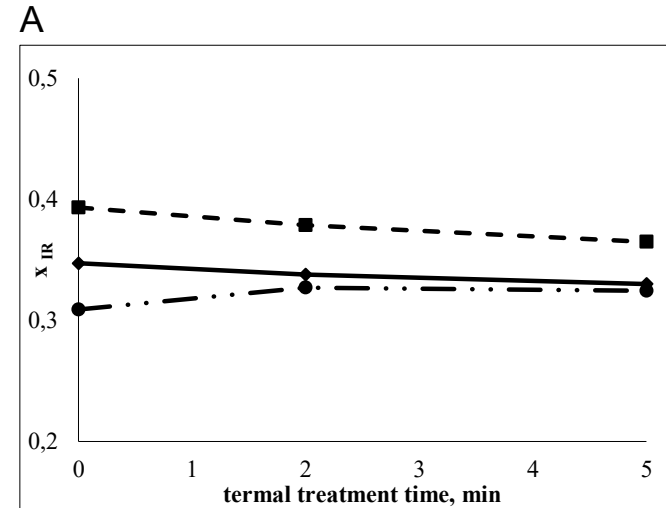

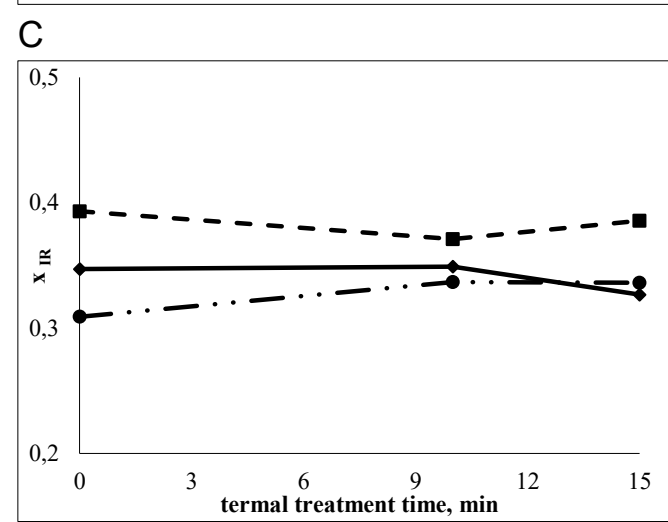

Figure 7. The changes of the content of ordered material (paracrystalline matter) $\mathbf{X I R}$ for the fibers investigated under the influence of thermal treatment: A) in air at temperature $180^{\circ} \mathrm{C}, \mathrm{B}$ ) in steam at temperature $134^{\circ} \mathrm{C}$, and $\mathrm{C}$ ) in water at temperature $120^{\circ} \mathrm{C}$ as a function of treatment time.

A)
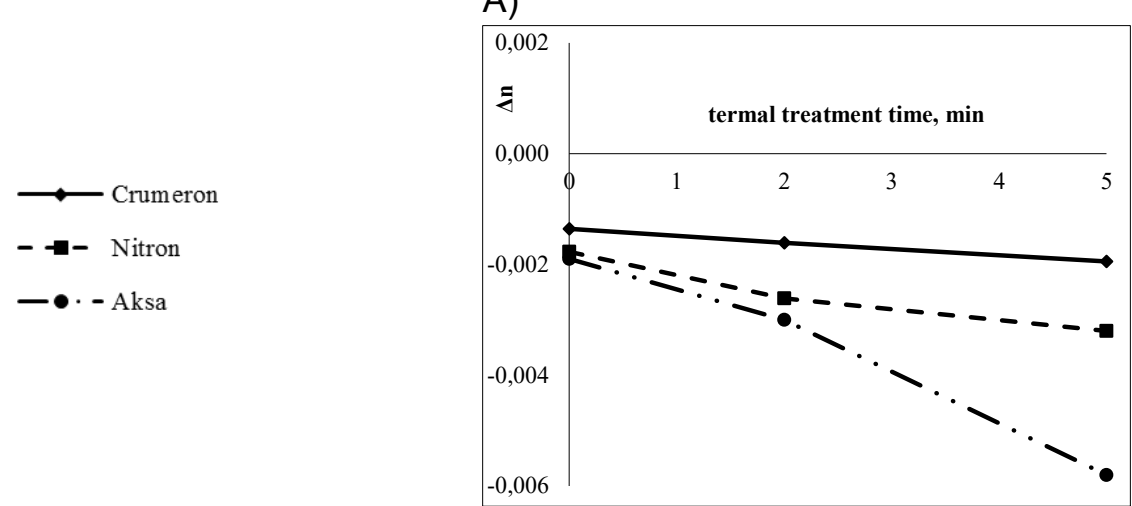

B)

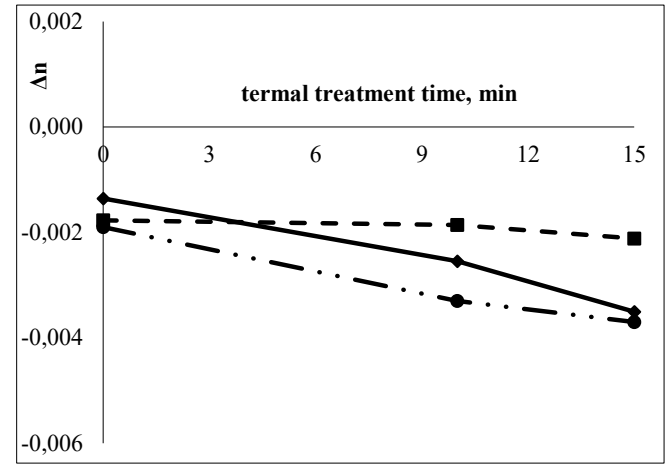

Figure 8. The changes in corrected optical birefringence $\mathrm{Dn}_{\text {cor }}$ under the influence of thermal treatment for the fibers investigated: $\mathrm{A}$ ) in air at temperature $180^{\circ} \mathrm{C} ; \mathrm{B}$ ) in water at temperature $120^{\circ} \mathrm{C}$ as function of treatment time. 
Table 6. The values of crystalline index $X_{\mathrm{c}}$ for the selected variants of thermal treatment fibers Crumeron and Nitron

\begin{tabular}{|c|c|c|}
\hline \multirow{2}{*}{ Medium of thermal treatment and parameters applied } & Crumeron & Nitron \\
\cline { 2 - 3 } & & \multicolumn{2}{|c|}{$x_{\mathrm{c}}$} \\
\hline Initial fibers & 0.607 & 0.611 \\
\hline Air at $180^{\circ} \mathrm{C}, 5 \mathrm{~min}$ & 0.566 & 0.547 \\
\hline Water at $120^{\circ} \mathrm{C}, 10 \mathrm{~min}$ & 0.586 & 0.619 \\
\hline Steam at $134^{\circ} \mathrm{C}, 15 \mathrm{~min}$ & 0.617 & 0.560 \\
\hline
\end{tabular}

\subsection{Discussion and interpretation of results}

\subsubsection{Changes in the molecular structure of the fibers investigated}

Analyzing the absorption spectra of the fibers investigated (examples in Figures 2, 3, and 4), one can observe - in the case of Aksa, Crumeron, and Nitron fibers - after thermal treatment at $>120^{\circ} \mathrm{C}$ for a longer time, the appearance of an absorption band at a wavelength of $\sim 1,649 \mathrm{~cm}^{-1}$. This band may be ascribed to the vibration of $\mathrm{C}=\mathrm{C}$ bonds [40], which according to data reported in a previous paper [14], occurs as the effect of thermal reconstruction of PAN macromolecules.

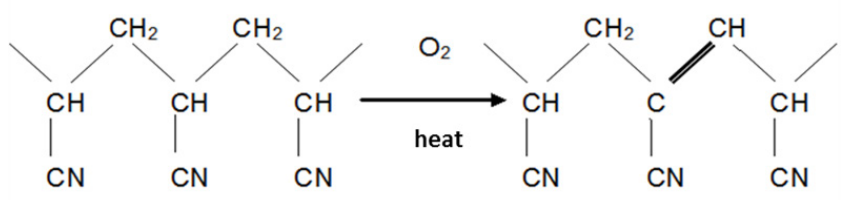

Their presence is shown in the yellow or brown color of the fiber as the reaction advances.

Taking into account the above fact related to the necessity of maintaining the esthetic values of the PAN fibers of the textile at the unchanged level (white color), all the processes of their thermal treatment should not be carried out under extremely drastic conditions, i.e., at excessively high temperature and for prolonged treatment times. The selection of the medium for thermal treatment is also of importance.

The analysis of the fiber absorption spectra in the aspect of changes in absorption values and characteristic absorption bands does not indicate particular differences in values before and after thermal treatment. This indicates the stability of the chemical constitution of the side groups in the comonomers, determining the fiber sorption capability in relation to, e.g., dyes, under the accepted conditions of preliminary thermal treatment of fibers (stabilization).

The changes in the fiber molecular coherence, found in the investigations, expressed by the value of CDT, should be considered in terms of the previously mentioned changes in the molecular structure of the PAN macromolecular chain (structure stiffening), combined with changes in the molecular structure, expressed by both changes in the content of paracrystalline material and its stability - resulting from the degree of its perfectness and the overall supramolecular structure - specific for PAN fibers.

Because of the presence of one type of comonomer in the macromolecules forming Aksa fibers and its smallest content in relation to the materials of the other two PAN fibers, this fiber is characterized by the strongest intermolecular interaction, as confirmed by the longest CDT.

The thermal treatment of the fiber at the highest temperature in air, due to the intensive reorientation process (Figure 8 ), leads to a decrease in the CDT value within 2 minutes to the value of CDT comparable to that of other fibers, for which practically no changes in CDT are observed upon heating in air over the whole time range.

The process of the thermal treatment of fiber in steam at a temperature of $134^{\circ} \mathrm{C}$ results in a clear increase in the molecular coherence of the fiber material to a level practically comparable with that of the shortest treatment time. This probably results from the intensive relative ordering of macromolecules in their paracrystalline material in the presence of water molecules (removing existing defects) and a decrease in the degree of fiber porosity.

The thermal treatment of fibers in water at the lowest temperature practically yields no changes in their molecular coherence because of the very weak thermal stimulus that is inactive in the restructuring of both the paracrystalline material and the overall supramolecular structure.

\subsubsection{Changes in the fiber's supramolecular structure}

\subsubsection{Changes in the content of the fiber's paracrystalline material}

The results of measurements obtained by various methods indicate small changes in the content of paracrystalline material in the investigated fibers under the influence of the thermal treatment variants. From a comparison of the measurement results of the fiber's paracrystallinity parameters $\left(x_{m}, x_{I R}\right.$, and $X_{C}$ ), it follows that the initial fibers show some differences in their values. The highest differences in these values occur in the case of the assessment by the spectrophotometric method, which may be connected with the different levels of relative perfection of the macromolecule order in the material of these 
fibers within paracrystalline areas and thereby with the groups responsible for the absorption of IR radiation.

The thermal treatment of PAN fibers results in decreased differences in the macromolecule order indexes of their materials and, in most cases, in a small decrease in the values. For the selected variants of thermal treatment of Nitron and Crumeron fibers, this result was confirmed by the results of WAXS.

Analyzing the results in terms of differences concerning initial fibers, one may conclude that IR absorption spectroscopy shows the highest sensitivity in determining differences and changes in the ordered material of PAN fibers.

\subsubsection{Changes in the overall orientation of PAN fibers}

The measurement results of changes in the overall orientation index of the fiber indicate a decrease in the index with increase in the treatment time in the case of all the temperature variants and the treatment media used. The highest decrease in the values involve the Aksa fibers during the treatment in air, which - as was already mentioned during the analysis of changes in CTD - can be related with the lowest perfectness level of the relative mutual order of macromolecules in the fiber's paracrystalline material, with a simultaneously minimized degree of fiber porosity.

\section{Conclusions}

The thermal treatment of PAN fibers with different molecular structures results in changes in both their molecular and supramolecular structures. The character and range of these changes do not show any significant relation with the differences in their initial structure. The essence of changes is directly connected with the chemical reconstruction of the acrylonitrile monomeric unit, which becomes apparent in the formation of $-\mathrm{C}=\mathrm{C}-$ bonds, and intensifies with increasing temperature and duration of thermal treatment. This restructuring leads to the appearance of fiber color and significant changes in the molecular coherence of the fiber material. These changes are accompanied by changes in the fiber's supramolecular structure, shown by a small decrease in the content of fiber paracrystalline material and the stabilization of its value with prolongation of the thermal treatment. No significant effect of the type of treatment medium on changes in the content of the fiber's paracrystalline material is observed.

Analyzing the changes of supramolecular fiber structure, a distinct decrease in the overall orientation index to various extents was observed for the fibers investigated, which intensified with the prolongation of thermal treatment regardless of the treatment medium used.

One may assume that the observed changes in both the molecular and supramolecular structures result in a definite change in the fiber's properties, especially mechanical and absorption properties, e.g., in relation to dyes. Taking into consideration the visual aspect connected with a change in the fiber color, which may be of importance in the case of dyeing fibers with bright or weak colors, the most appropriate solution to the problem of thermal stabilization of PAN fibers under industrial condition is short-duration treatment in the medium of steam at a temperature of about $130^{\circ} \mathrm{C}$

\section{ACKNOWLEDGMENTS}

This work was financed from funds assigned for 14-148-1-2117 statuary activity by Department of Material and Commodity Sciences and Textile Metrology, Lodz University of Technology, Poland.

\section{References}

[1] English Patent 864096.

[2] German patent 975540.

[3] French patent 1267240.

[4] Bhemdrup, J., Faserforsch, u. (1961). Textiltechn, 12, 133, 208.

[5] Izumi, Z., Kiuchi, K., Watanabe, M. (1963). Copolymerization of acrylonitrile and $p$-sodium styrene sulfanate. Journal of Polymer Science Part A: General Papers, A-1, 2, 705.

[6] Boguń, M., Mikołajczyk, T. (2006). Fibres \& Textiles in Eastern Europe, 3(57), 19-22.

[7] Mikołajczyk, T., Boguń, M., Kowalczyk, A. (2005) Fibres \& Textiles in Eastern Europe, 3(51), 30-34.

[8] Brzezińska, M., Król, P., Boguń, M. (2012) Engineering of Biomaterials, 15, 116-117, 100-103.

[9] Mikołajczyk, T., Szparaga, G. (2009). Influence of fibre formation conditions on the properties of nanocomposite PAN fibres containing Nanosilver. Fibres and Textiles in Eastern Europe, 75(4), 30-36.

[10] Mikołajczyk, T., Szparaga, G., Janowska, G. (2009) Influence of silver nano-additive amount on the supramolecular structure, porosity, and properties of polyacrylonitrile precursor fibers. Polymers for Advanced Technologies, 20(12), 1035-1043.

[11] Houtz, R. C. (1950). "Orlon" acrylic fiber: chemistry and properties. Textile Research Journal, 20, 786.

[12] Grassie, N., Hay, N. J., Mc Neill J. (1958). Coloration in acrylonitrile and methacrylonitrile polymers. Journal of Polymer Science, 31, 205.

[13] Schurz, J. J. (1958). Discoloration effects in acrylonitrile polymers. Journal of Polymer Science, 28, 438.

[14] Conley, R. T., Bieron, J. (1963). Examination of the oxidative degradation of polyacrylonitrile using infrared spectroscopy. Journal of Applied Polymer Science, 7, 1757.

[15] Fester, W. (1965). Textil-Rundsch., 20, 1.

[16] Koszeliew, I. W., Sokołowskij, W. H. (1993). Fibre Chemistry, 5, 8.

[17] Fimcer, E., Fros, W. (1992). Fibre Chemistry, 2, 14.

[18] Sawczenko, G., Bondarenko, W. M., Azarowa, M. T. (1994). Fibre Chemistry, 6, 21.

[19] Azarowa, M. T., Bondarenko, W. M., Sawczenko, G. (1995). Fibre Chemistry, 1, 10. 
[20] Kakida, H., Tashiro, K. (1998). Mechanism and kinetics of stabilization reactions of polyacrylonitrile and related copolymers IV. Effects of atmosphere on isothermal DSC thermograms and FT-IR spectral changes during stabilization reaction of acrylonitrile/methacrylic acid copolymer. Polymer Journal, 30, 463-469.

[21] Kalasznik, A. T., Zlatoustowa, L. A., et al. (1999). Fibre Chemistry, 31, 425.

[22] Warszawskij, W. J. (1994). Fibre Chemistry, 1, 18.

[23] Wołkowicz, K. (1987). Przegląd włókienniczy, 14.

[24] Szparaga, G., Mikołajczyk, T., Fraczek-Szczypta, A. (2013). Fibres \& Textiles in Eastern Europe, 6(102), 33-38.

[25] Boguń, M. (2008). Zeszyty naukowe, Włókiennictwo, Politechnika Łódzka, 64, 19-39.

[26] Glicińska, E., Babet, K. (2013). Fibres \& Textiles in Eastern Europe, 3(99), 42-47.

[27] Szparaga, G. (2012). Zeszyty naukowe, Włókiennictwo, Politechnika Łódzka, 69, 41-58.

[28] Marczak, E., Marczak, P. (2009). Przegląd WłókienniczyWłókno, Odzież, Skóra, 1, 32-36.

[29] Marczak, P., Marczak, E. (2009). Przegląd WłókienniczyWłókno, Odzież, Skóra, 4, 37-40.

[30vMarczak E, Marczak P. (2003). Przegląd Włókienniczy+Technik Włókienniczy, 3, 3-5.

[31] Mikołajczyk, T. (1997). Zeszyty naukowe Pt $\mathrm{nr} 781$, Rozprawy Naukowe Z 243.

[32] AKSA (Aksa Akrilik Kimya Sanayii A.i). AKSA The world leader in acrylic fiber. Chopped carbon fiber. Retrieved October 26, 2011. Website: http://www.semplastik.com.tr/ pdf/VIPAGEV/Chopped\%20Carbon\%20Fiber.pdf.

[33] Lipp-Symonowicz, B., Sztajnowski, S., Kułak, A. (2012). Infrared radiation. IR spectroscopy as a possible method of analysing fibre structures and their changes under various impacts. Website: www.intechopen.com, http:// cdn.intechopen.com/pdfs-wm/27933.pdf.
[34] Bieniek, A., Lipp-Symonowicz, B., Sztajnowski, S. (2009). Influence of the structures of polyamide 6 fibers on their ageing under intensive insolation conditions [in English]. Polimery, 11-12, 840.

[35] Bell, R. J. (1972). Introductory Fourier transform infrared spectroscopy. New York, Academic Press.

[36] Hirschfeld, T. (1979). Fourier transform infrared spectroscopy. Ferraro - Basile, eds. Applications to Chemical Systems. Vol. 2. New York, Academic Press.

[37] Dechant, J. (1972). Ultrarotspektroskopische Untersuchungen an Polymeren, Berlin, Akademie-Verlag.

[38] Witenhafer, D. E., Koenig, J. L. (1968). Infrared studies of poly[3,3-bis(chloromethyl)oxacyclobutane]. II. Polymorphic transformation. J Macromolecular Science Part B, 2, 247.

[39] Ueberreiter, K. (1968). Diffusion in polymers. New York, NY: Academic Press.

[40] Lindenmeyer, P. H., Hosemann, R. J. (1963). Permanent polarization in poly(acrylonitrile). Journal of Applied Physics, 34, 42.

[41] Urbańczyk, G. W. (1970). Fizyka Włókna, WNT, Warszawa.

[42] Pluta, M. (1982). Mikroskopia optyczna, PWN, Warszawa.

[43] Dorau, K., Pluta M. (1981). Przegląd Włókienniczy, 2, 70.

[44] Urbańczyk, G. W. (2002). Fizyka Włókna, PŁ, Łódź.

[45] Hindeleh, A. M., Johnson, D. J. (1971). The resolution of multipeak data in fibre science. Journal of Physics $D$ : Applied Physics, 4, 259.

[46] Hindeleh, A. M., Johnson, D. J. (1978). Crystallinity and crystallite size measurement in polyamide and polyester fibres. Polymer, 19, 27-35.

[47] Sztajnowski, S., Puchalski, M., Krucińska, I., Sulak, K. (2012). Fibres \& textiles in Eastern Europe, 20, 6B (96), 89. 